Revista Destaques Acadêmicos, Lajeado, v. 9, n. 1, 2017. ISSN 2176-3070

DOI: http://dx.doi.org/10.22410/issn.2176-3070.v9i1a2017.1289

www.univates.br/revistas

\title{
COMO A CULTURA ORGANIZACIONAL INFLUENCIA NA ATUAÇÃO DOS LÍDERES
}

\author{
Priscila Lanzini Bastos ${ }^{1}$, Carlos Candido da Silva Cyrne ${ }^{2}$
}

Resumo: Este artigo objetivou analisar na literatura a influência que a cultura organizacional tem sobre a atuação dos líderes empresariais. Havendo como objetivos específicos: Realizar um levantamento da literatura sobre cultura organizacional e liderança; Comparar, em diferentes estudos científicos, a influência que a cultura organizacional tem sobre a liderança empresarial; Identificar as culturas organizacionais que mais contribuem para o sucesso dos líderes, liderados e consequentemente para as empresas. A metodologia foi um estudo exploratório e bibliográfico, realizado através de análise qualitativa e bibliometria. Os resultados demonstraram que cultura e liderança se confundem no contexto da literatura, visto que o impacto ocorre da cultura sobre a liderança e da liderança sobre a cultura. Além disso, não há uma liderança ou uma cultura que seja melhor ou pior de modo geral, apenas lideranças e culturas que melhor se adaptam ao contexto atual da organização e da necessidade do setor que a empresa atua.

Palavras-chave: Liderança. Cultura organizacional. Administrador.

\section{INTRODUÇÃO}

A cultura organizacional influencia diretamente a condução da empresa, seja no trabalho desenvolvido nos setores, na inovação em produtos, na capacidade dos profissionais que atuam nela, no clima organizacional, nas estratégias de liderança, entre outros fatores que garantem inclusive a sobrevivência da organização. Segundo Barreto et al. (2013, p. 34-35) "a cultura organizacional permeia os diversos setores e níveis das empresas, exercendo reconhecida influência sobre diversos aspectos, desde o comportamento de seus profissionais e gestores até a formulação de estratégias e o desempenho organizacional".

1 Graduação em Administração pela Ulbra, cursando MBA em Gestão Estratégica de Pessoas pela Univates.

2 Orientador. Graduação em Administração pela UNISC, Mestre em Engenharia da Produção pela UFSM e Doutor em Ciências pela Univates. 
No âmbito da liderança destaca-se que o líder tem papel fundamental sobre a direção e os impactos sobre a empresa, além disso contribui para criar, manter e mudar aspectos culturais através de sua gestão (BARRETO et al., 2013). Afinal, a liderança influencia no comportamento das pessoas, na administração da organização e no modo como os clientes veem a empresa. Segundo Chiavenato (2003, p. 122) a liderança "é essencial em todas as funções da Administração: o administrador precisa conhecer a natureza humana e saber conduzir as pessoas, isto é, liderar".

Diante desta perspectiva, este estudo objetiva analisar na literatura a influência que a cultura organizacional tem sobre a atuação dos líderes empresariais. Tendo como objetivos específicos: Realizar um levantamento da literatura sobre cultura organizacional e liderança; Comparar em diferentes estudos científicos, a influência que a cultura organizacional tem sobre a liderança empresarial; Identificar as culturas organizacionais que mais contribuem para o sucesso dos líderes, liderados e consequentemente para as empresas.

Outrossim, este estudo justifica-se pela importância que a liderança tem na sobrevivência de qualquer organização, influenciada pela cultura organizacional ou recriando esta cultura. Visto que conhecer os aspectos de liderança e cultura organizacional que influenciam para o sucesso e perpetuação de uma empresa são de fundamental importância para qualquer organização.

Além disso, esta estudante busca entender possíveis erros e acertos que podem estar ocorrendo nas organizações em que atua ou irá atuar, podendo contribuir para potencializar os acertos e mitigar erros. Por fim, é relevante a contribuição deste estudo no meio acadêmico como fonte de pesquisa na instituição de ensino como recurso em seu banco de dados e disponível para consulta.

\section{CULTURA OGANIZACIONAL}

Conceitualmente, no entendimento de Thévenet (1989, p. 154, apud RIBEIRO, 2008, p. 204) "a cultura é um conjunto de hipóteses fundamentais que estruturam a generalidade dos comportamentos da gestão da empresa; é fruto e uma longa experiência, resulta de um longo processo de aprendizagem". Barreto et al. (2013, p. 35) declara que:

O estudo sobre cultura organizacional está fundamentado em paradigmas oriundos da Antropologia, da Sociologia, da Psicologia e das Ciências Políticas. Segundo Allaire e Firsirotu (1984), a revisão dessas influências pode ser agrupada em dois blocos. O primeiro percebe a cultura organizacional como um sistema sociocultural, partindo da ideia de que os componentes sociais e estruturais estão completamente integrados à dimensão simbólica e ideológica da organização. [...] O segundo bloco percebe a cultura organizacional 
como um sistema de ideias, em que ela não representa meramente uma rede de padrões de comportamentos, mas um conjunto de mecanismos de controle para modelar tais comportamentos.

Ainda, os autores revelam que a cultura é caracterizada por três níveis: "artefatos - entendidos como estruturas e processos organizacionais visíveis; valores - que são as estratégias, os objetivos e as filosofias; pressupostos - que se referem a crenças, percepções e pensamentos, muitas vezes inconscientes" (BARRETO et al., 2013, p. 36, grifo do autor).

A cultura organizacional influencia no gerenciamento de empresas e seu impacto molda as estratégias, as necessidades de mudanças e a própria sobrevivência no mercado. Segundo Ribeiro (2008) a cultura influencia na mudança, na estratégia e no trabalho.

Por sua vez, Chiavenato (2010, p. 29, grifo do autor) declara que:

[...] cultura organizacional [...] deixou de privilegiar as tradições antigas e passadas e passou a concentrar-se no presente, fazendo com que o conservantismo e a manutenção do status quo cedessem lugar a inovação e mudança de hábitos e de maneiras de pensar e agir.

As atitudes de todo ser humano sofrem influência do cotidiano em que vivem, das percepções familiares, do círculo de amizades, das tecnologias a que têm acesso, da empresa em que atuam, entre outras formas de intervenção. Dentro do contexto da empresa, as pessoas são influenciadas pela cultura da organização. Ribeiro (2008, p. 29) enfatiza que a "[...] cultura organizacional [...] são os valores, crenças e atitudes da empresa que os empregados compartilham".

A atitude da empresa e seus líderes influencia no comportamento de seus liderados, outrossim, Chiavenato (2010) revela que as empresas bemsucedidas estão percebendo a importância de práticas gerenciais e culturas que privilegiem a participação dos funcionários, incentivando-os a terem valores e objetivos favoráveis a organização.

Ribeiro (2008, p. 169-170) traz aspectos a serem considerados na cultura organizacional:

- força da cultura na empresa (normas culturais enraizadas ou não);

- homogeneidade da cultura (compatibilização de subculturas);

- adequação das cultura às estratégias até então seguidas;

[...]

- atitudes para com o pessoal (confiança e participação), com a empresa (lealdade, espírito de equipe, identificação com a empresa). 
Assim, percebe-se que a equipe de trabalho deve compartilhar da cultura da empresa para que esta, implante estratégias bem-sucedidas, as mudanças sobre os aspectos culturais de uma organização podem ser difíceis, mas normalmente são necessários. Para Ribeiro (2008) uma das maiores polêmicas em organizações envolve a possibilidade de mudar ou não a cultura, mas deixa claro que é necessário planejamento para este processo ocorrer.

Diante da necessidade de mudança é fundamental entender os diferentes tipos de cultura, conforme Barreto et al. (2013, p. 36-37, grifo dos autores) há quatro:

- Cultura clã - enfatiza o desenvolvimento das pessoas e valoriza a participação nas tomadas de decisões. A autoridade flui muito bem quando emana de membros comprometidos com o sistema há muito tempo. Os líderes tendem a assumir uma postura participativa, oferecendo suporte e facilitando a interação, a confiança e a lealdade. - Cultura inovativa - é permeada por pressupostos de mudança e flexibilidade. Os fatores de motivação incluem crescimento, estímulo, diversificação e criatividade na tarefa. Os líderes tendem a ser empreendedores e idealistas. Apreciam correr riscos, gostam de prever o futuro e também se preocupam em obter recursos, suporte e imagem externa. A ênfase está voltada para a aquisição de novos conhecimentos em produtos e/ou serviços.

- Cultura de mercado - tem como orientação tendências de mercado e bases seguras de clientes. Os fatores de motivação incluem competição e consecução de resultados preestabelecidos. Os líderes tendem a ser diretivos, realizadores, competidores, orientados para o objetivo e estão constantemente fornecendo recursos e encorajando a produtividade. São severos e exigentes. O elemento que fundamenta a organização é a ênfase no vencedor.

- Cultura hierárquica - esta cultura é permeada por pressupostos de estabilidade e reflete os valores e normas associados à burocracia. Os empregados aceitam bem a autoridade que emana de papéis formalmente estabelecidos, de regras e regulamentos impostos. Os fatores de motivação incluem segurança e ordem. Os líderes tendem a ser conservadores em relação aos problemas de natureza técnica.

Compreender o contexto da empresa é primordial para qualquer processo que envolve a cultura organizacional, bem como, o trabalho do líder influencia para atingir metas, objetivos e necessidades de mudança.

\section{LIDERANÇA}

A liderança pode ter efeito positivo ou não sobre uma organização, bem como sobre a cultura organizacional, porém é preciso considerar que a liderança também influencia a cultura. Portanto é preciso ter presenta a ideia de influência mútua. Chiavenato (2004) conceitua liderança como uma 
forma de dominação ou controle, na qual a função do líder é expor e fazer cumprir critérios de performance para atingir objetivos organizacionais. Sendo uma análise puramente hierárquica, na qual há o "chefe" que manda e o "empregado" que obedece.

Ribeiro (2008) enfatiza que a liderança não é autossustentável, ela é construída dia após dia, para isso as empresas precisam cercar-se de profissionais capazes de liderar e ter um planejamento estratégico moderno. Além disso, o líder fortalece a imagem da organização, seja positivo ou negativamente.

Segundo Gimenes et al. $(2015$, p. 2):

A Liderança é a capacidade de gerenciar um grupo de pessoas, fazendo com que esse grupo gere lucratividade para a organização em trabalho em equipe. O líder tem um importante papel para o desenvolvimento de uma empresa, ele é o espelho do ambiente, um líder com um bom conhecimento e atitude ajuda no progresso da organização.

O líder deve ser capaz de gerenciar sua equipe, de acordo com Chiavenato (2010) o líder deve cuidar para que sua equipe tenha: objetivos claros, percepção integrada, divisão de trabalho grupal, decisões conjuntas, liderança compartilhada, novas ideias para soluções de problemas, e avaliação da eficácia.

Ribeiro (2008, p. 33) enfatiza que "as visões de um líder têm de ser compartilhadas com sua equipe e sua equipe precisa concordar em apoiá-las". A forma de gerenciamento do líder influencia sua equipe, que por sua vez é influenciada e influencia na cultura organizacional.

De acordo com Bonel (2013), há três tipos principais de liderança:

- líder autoritário: o líder define os processos, quem faz, não considera a opinião dos subordinados, tem uma equipe desmotivada. Porém é excelente em momentos de crise externa.

- líder democrático: tem seu foco nas pessoas, estimula os funcionários, decide em equipe. Mas precisa ter cuidado, pois a responsabilidade sobre os resultados da equipe é dele.

- líder liberal: dá total liberdade para sua equipe trabalhar, normalmente funciona com equipes muito experientes. Este tipo de líder não traça planos e não se envolve no trabalho em equipe.

Bonel (2013) enfatiza que o líder precisa gerenciar uma equipe, por isso, deve ter a capacidade de influenciar e gerenciar diferentes perfis de funcionários, diante desta perspectiva, conclui que o líder deve ser 80\% democrático, 15\% liberal e $5 \%$ autoritário.

Além disso, Gonçalves et al. (2015, p. 91) elenca dois estilos de liderança com denominações distintas das de Bonel (2013): “[...] o líder transacional 
motiva os subordinados para o desempenho esperado, o líder transformacional normalmente inspira seguidores a fazer mais do que o inicialmente esperado".

\section{METODOLOGIA}

Quanto à caracterização segundo o objetivo geral desta pesquisa, este estudo é exploratório, que de acordo com Gil (2008, p. 27) "são desenvolvidas com o objetivo de proporcionar visão geral, de tipo aproximativo, acerca de determinado fato".

Quanto aos procedimentos técnicos, torna-se uma pesquisa bibliográfica tanto para o embasamento teórico, como para a análise de dados. Na compreensão de Vergara (2006, p. 48), "pesquisa bibliográfica é o estudo sistematizado desenvolvido com base em material publicado em livros, revistas, jornais, redes eletrônicas, isto é material acessível ao público em geral".

Com relação ao tratamento dos dados consiste em um estudo qualitativo, com o uso de dados secundários. Aaker, Kumar e Day (2004, p. 130) determinam que os "dados secundários são aqueles que foram coletados por pessoas ou agências para outros propósitos que não a resolução do problema específico que temos em mãos" e Malhotra (2011, p. 122) enfatiza que "a pesquisa qualitativa proporciona melhor visão e compreensão do cenário do problema".

$\mathrm{Na}$ análise de dados utiliza-se o método de bibliometria que consiste em "um conjunto de leis e princípios empíricos que contribuem para estabelecer os fundamentos teóricos" (GUEDES; BORSCHIVER, 2005, p. 2). A técnica que norteia esta pesquisa são as Leis de Zipf:

Que permitem estimar as frequências de ocorrência das palavras de um determinado texto científico e tecnológico e a região de concentração de termos de indexação, ou palavras-chave, que um pequeno grupo de palavras ocorre muitas vezes e um grande número de palavras é de pequena frequência de ocorrência (GUEDES; BORSCHIVER, 2005, p. 4).

Considera-se nesta pesquisa artigos, teses e dissertações publicados no Scielo e Capes, utilizando-se palavras-chave como "cultura organizacional", "liderança", "líderes" e "cultura", levando em consideração estudos recentes dos últimos dez anos (2006-2016). Cada estudo é selecionado através de leitura do resumo para identificar os que vem de encontro com os objetivos propostos, após realiza-se o comparativo do mesmo por meio de fichamento para análise e discussão dos resultados. 


\section{ANÁLISE DOS RESULTADOS}

Para atingir ao objetivo proposto comparou-se nove estudos, publicados no Scielo e no Capes nos últimos dez anos, identificados no quadro a seguir e detalhados na sequência:

Quadro 1 - Relação de estudos

\begin{tabular}{|c|c|c|c|}
\hline $\mathbf{N}^{\circ}$ & Referências & Palavras-chave & Metodologia \\
\hline 1 & $\begin{array}{l}\text { BARRETO, Leilianne M.T.S. } \\
\text { et al. Cultura organizacional } \\
\text { e liderança: uma relação pos- } \\
\text { sível? R. Adm., São Paulo, v. } \\
\text { 48, n. 1, p. 34-52, } 2013 \text {. }\end{array}$ & $\begin{array}{l}\text { - Cultura organi- } \\
\text { zacional. } \\
\text { - Liderança. } \\
\text { - Setor de restau- } \\
\text { rantes. }\end{array}$ & $\begin{array}{l}\text { - Descritivo } \\
\text { - Correlacional } \\
\text { - Quantitativa } \\
\text { - Software estatístico SPSS } \\
\text { - Pesquisa de campo in loco } \\
\text { - Aplicação de questionários } \\
\text { - Escala Likert de } 1 \text { a } 6 \\
\text { - Corredor turístico da cidade de } \\
\text { Natal (Ponta Negra, Redinha, Praia } \\
\text { do Meio, Praia dos Artistas e Via } \\
\text { Costeira) } \\
\text { - } 31 \text { restaurantes }\end{array}$ \\
\hline 2 & $\begin{array}{l}\text { KICH, Juliane I.D.F.; PEREI- } \\
\text { RA, Mauricio F. A influência } \\
\text { da liderança, cultura, estru- } \\
\text { tura e comunicação orga- } \\
\text { nizacional no processo de } \\
\text { implantação do planejamen- } \\
\text { to estratégico. Cad. EBAPE. } \\
\text { BR, v. 9, n }{ }^{\circ} 4 \text {, artigo 6, Rio de } \\
\text { Janeiro, Dez. } 2011 \text {. }\end{array}$ & $\begin{array}{l}\text { - Planejamento. } \\
\text { - Estratégia. } \\
\text { - Implantação. }\end{array}$ & $\begin{array}{l}\text { - Estudo de caso } \\
\text { - Qualitativa } \\
\text { - Descritiva } \\
\text { - Análise documental } \\
\text { - Entrevista semiestruturadas em } \\
\text { - profundidade } \\
\text { - Questionário } \\
\text { - Observação sistemática } \\
\text { - } 15 \text { entrevistados } \\
\text { - Aplicados } 14 \text { questionários }\end{array}$ \\
\hline 3 & $\begin{array}{l}\text { TEZZA, Piery et al. Direcio- } \\
\text { nadores do processo de ino- } \\
\text { vação: o papel da estratégia, } \\
\text { liderança e cultura. Navus } \\
\text { - Revista de Gestão e Tecno- } \\
\text { logia. Florianópolis, SC, v. 3, } \\
\text { n. 2, p. } 77 \text { - 88, jul./dez. } 2013 \text {. }\end{array}$ & $\begin{array}{l}\text { - Inovação. } \\
\text { - Front End da } \\
\text { Inovação. } \\
\text { - Gestão da Ino- } \\
\text { vação. } \\
\text { - Direcionadores } \\
\text { da Inovação. }\end{array}$ & $\begin{array}{l}\text { - Estudo empírico } \\
\text { - Pesquisa exploratória } \\
\text { - Estudo de caso } \\
\text { - Entrevista de grupo focal } \\
\text { - Análise de conteúdo de Bardin } \\
\text { - Documental } \\
\text { - Observação não participante } \\
\text { - } 7 \text { participantes }\end{array}$ \\
\hline 4 & $\begin{array}{l}\text { SILVA JUNIOR, Annor; } \\
\text { VASCONCELOS, Kátia C.A.; } \\
\text { SILVA, Priscilla O.M. Desen- } \\
\text { volvimento organizacional } \\
\text { e a formação de lideranças: } \\
\text { um estudo no setor de papel } \\
\text { e celulose. R. Adm. FACES } \\
\text { Journal, Belo Horizonte, v. 9, } \\
\text { n. 2, p. 15-31, abr./jun. 2010. }\end{array}$ & $\begin{array}{l}\text { - Desenvolvi- } \\
\text { mento organi- } \\
\text { zacional. } \\
\text { - Mudança orga- } \\
\text { nizacional. } \\
\text { - Formação de } \\
\text { lideranças. } \\
\text { - Pesquisa-ação. } \\
\text { - Papel e celulose. }\end{array}$ & $\begin{array}{l}\text { - Pesquisa-ação } \\
\text { - Pesquisa qualitativa } \\
\text { - Estudo de caso descritivo-analítico } \\
\text { - Análise documental } \\
\text { - Observação participante } \\
\text { - Entrevista semiestruturada } \\
\text { - } 277 \text { participantes }\end{array}$ \\
\hline
\end{tabular}




\begin{tabular}{|c|c|c|c|}
\hline $\mathrm{N}^{\mathbf{0}}$ & Referências & Palavras-chave & Metodologia \\
\hline 5 & $\begin{array}{l}\text { DOROW, Patricia F. et al. } \\
\text { Barreiras e facilitadores para } \\
\text { a geração de ideias. Revista } \\
\text { Eletrônica de Estratégia \& } \\
\text { Negócios, Florianópolis, v.6, } \\
\text { n.3, set./dez.2013. }\end{array}$ & $\begin{array}{l}\text { - Inovação. } \\
\text { - Geração de } \\
\text { ideias. } \\
\text { - Cultura. }\end{array}$ & $\begin{array}{l}\text { - Pesquisa exploratória-descritiva } \\
\text { - Qualitativa } \\
\text { - Entrevista } \\
\text { - Dois gerentes }\end{array}$ \\
\hline 6 & $\begin{array}{l}\text { RAMALHEIRA, Pedro R.S. } \\
\text { O impacto da cultura portu- } \\
\text { guesa e da pró-atividade na } \\
\text { liderança: um estudo explo- } \\
\text { ratório. 2013. 154f. Disserta- } \\
\text { ção (Mestrado em Planeja- } \\
\text { mento e Gestão Estratégica) } \\
\text { - Universidade Autônoma } \\
\text { de Lisboa, Portugal, 2013. }\end{array}$ & $\begin{array}{l}\text { - Liderança. } \\
\text { - Pró-atividade. } \\
\text { - Dimensões Cul- } \\
\text { turais de Hofs- } \\
\text { tede. }\end{array}$ & $\begin{array}{l}\text { - Estudo exploratório } \\
\text { - Quantitativa } \\
\text { - Questionário } \\
\text { - } 119 \text { respondentes } \\
\text { - Software SPSS }\end{array}$ \\
\hline 7 & $\begin{array}{l}\text { REIS, Patricia N.C. et al. } \\
\text { O impacto da liderança na } \\
\text { construção da cultura or- } \\
\text { ganizacional: um estudo de } \\
\text { caso entre alunos de uma IES } \\
\text { privada. In: SIMPÓSIO DE } \\
\text { EXCELÊNCIA EM GESTÃO } \\
\text { E TECNOLOGIA, IX. Rio de } \\
\text { Janeiro: Associação Educa- } \\
\text { cional Dom Bosco, 2012. }\end{array}$ & $\begin{array}{l}\text { - Liderança } \\
\text { - Estilos de lide- } \\
\text { rança } \\
\text { - Cultura organi- } \\
\text { zacional }\end{array}$ & $\begin{array}{l}\text { - Pesquisa descritiva } \\
\text { - Estudo de caso } \\
\text { - Quantitativa } \\
\text { - Questionário } \\
\text { - } 80 \text { respondentes }\end{array}$ \\
\hline 8 & $\begin{array}{l}\text { GONÇALVES, Andressa et } \\
\text { al. A relação entre liderança } \\
\text { e cultura organizacional: um } \\
\text { estudo realizado em uma } \\
\text { IES. GEPROS. Gestão da } \\
\text { Produção, Operações e Sis- } \\
\text { temas, Bauru, Ano 10, n. 2, p. } \\
\text { 85-100, abr./jun. 2015. }\end{array}$ & $\begin{array}{l}\text { - Níveis de Cul- } \\
\text { tura. } \\
\text { - Liderança. } \\
\text { - Gestão. } \\
\text { - Instituição de } \\
\text { Ensino Supe- } \\
\text { rior. }\end{array}$ & $\begin{array}{l}\text { - Descritiva e Quantitativa } \\
\text { - Questionário in loco } \\
\text { - Survey } \\
\text { - Escala de Likert } \\
\text { - Software SPSS } \\
\text { - Correlação de Spearman } \\
\text { - } 94 \text { respondentes }\end{array}$ \\
\hline 9 & $\begin{array}{l}\text { ESTOL, Kátia M.F.; FERREI- } \\
\text { RA, Maria C. O Processo } \\
\text { Sucessório e a Cultura Orga- } \\
\text { nizacional em uma Empresa } \\
\text { Familiar Brasileira. RAC, v. } \\
\text { 10, n. 4, p. 93-110 Out./Dez. } \\
\text { 2006. }\end{array}$ & $\begin{array}{l}\text { - Cultura organi- } \\
\text { zacional. } \\
\text { - Sucessão. } \\
\text { - Empresa fami- } \\
\text { liar. }\end{array}$ & $\begin{array}{l}\text { - Questionário } \\
\text { - Escala de Ferreira e Asmar (2000) } \\
\text { e ANOVA } \\
\text { - } 197 \text { respondentes } \\
\text { - Três unidades } \\
\text { - Empresa familiar } \\
\text { - Sucessão familiar }\end{array}$ \\
\hline
\end{tabular}

Fonte: Dos autores (2017).

O artigo de Barreto et al. (2013) discutiu as relações entre a cultura organizacional e a liderança desempenhada pelos gestores no contexto de 37 restaurantes de uma capital brasileira. Foram utilizados questionários para entender as relações entre quatro tipos de culturas organizacionais: cultura clã: que enfatiza o desenvolvimento das pessoas e valoriza a participação nas tomadas de decisões; cultura inovativa que pressupõe mudança e 
flexibilidade e os líderes tendem a ser empreendedores e idealistas, corre-se riscos, preocupa-se com a imagem e o futuro, buscam inovação, conhecimento em produtos e serviços; cultura de mercado é orientada para o mercado e tem bases seguras de clientes, há competição e resultados preestabelecidos, líderes diretivos, realizadores, competidores, severos, exigentes, orientados para a produtividade; e cultura hierárquica que pressupõe estabilidade e reflete os valores e normas associados à burocracia, tem autoridade formal, imposição de regras e regulamentos e liderança conservador. E dois tipos de lideranças: transformacional na qual ocorre influencia mútua entre líderes e liderados, envolve o interesse pelas pessoas, os líderes inspiram e motivam, são carismáticos, estimulam novas ideias e delegam funções; e transacional em que as atribuições e condições de empregabilidade são claras, há códigos disciplinares e estrutura de benefícios, as recompensas são resultado de esforço, os líderes são negociadores e alocadores de recursos, atua na correção do trabalho por feedback e reforço negativo.

Neste estudo evidenciou-se que a maioria dos restaurantes são negócios familiares que sofrem grande influência de seus fundadores. Os autores ponderam que as lideranças que atuam com punições e sanções têm maior relacionamento com culturas de mercado ou hierárquica e que as lideranças transformacionais atuam melhor com culturas clã e inovativa, entretanto há predomínio das culturas clã e inovativa entre os sujeitos estudados. Evidenciouse que a cultura e liderança influenciam-se mutuamente, porém os autores enfatizaram haver outros estudos que afirmam que a liderança influencia na construção da cultura da empresa.

Gonçalves et al. (2015) buscaram identificar os estilos de liderança e o tipo de cultura organizacional presente em uma instituição de ensino superior (IES), bem como a relação entre esses dois artefatos no contexto educacional estudado. Realizaram um estudo descritivo e correlacional, pesquisa quantitativa por survey e aplicação de um questionário in loco a 94 gestores da IES. Identificaram os mesmos tipos de cultura de Barreto et al. (2013): clã, hierárquica, inovativa e de mercado, bem como os mesmos estilos de liderança: a transacional e a transformacional. Os resultados identificaram a cultura de clã como a mais presente na instituição estudada, sendo identificada pelo ambiente familiar, liberdade para opinar e sugerir melhorias e que valoriza o trabalho em equipe, já a cultura menos representada é a inovativa. No contexto do estilo de liderança a mais identificada entre os respondentes é a transformacional, onde há interação entre as pessoas, cria-se níveis de motivação favoráveis tanto aos líderes como aos liderados.

O estudo de Ramalheira (2013) buscou avaliar qual, ou quais, os estilos de liderança que melhor se adequam a cada ambiente cultural. Foi realizada uma pesquisa exploratória e quantitativa, através da aplicação de um questionário online a 119 com experiência profissional de mais de 10 anos ou com mais de 5 anos na liderança de equipes, os dados foram analisados pelo software SPSS. O 
autor enfatiza que cultura e liderança são aspectos indissociáveis, pois a cultura não é apenas uma das variáveis mais importantes que tem impacto no exercício da liderança, mas que também influencia outras variáveis como as normas da organização e as expectativas dos liderados. Afirma que os valores culturais têm $70 \%$ de efeito sobre o estilo de liderança dos gestores. Além disso, enfatiza que a liderança impacta na pró-atividade e na eficiência organizacional. Por fim, revelam que não há uma cultura ou liderança única que seja melhor ou pior, mas que cada modelo é percebido diferente em uma organização, visto que é fundamental conhecer as culturas locais e os estilos de liderança mais eficazes em cada contexto organizacional.

Reis et al. (2013) verificou o impacto da liderança na construção da cultura organizacional, por meio de um estudo descritivo e aplicação de 80 questionário. Os autores trabalharam com os três estilos de liderança de Chiavenatto: Liderança Autocrática: o líder exerce um nível elevado de poder sobre a equipe. As pessoas que compõem a equipe não têm muitas oportunidades para apresentar sugestões, mesmo que estas sejam do interesse da equipa ou da organização. Liderança Democrática: Há debate e decisões em grupo sob o estímulo e assistência do líder. O líder procura ser um membro normal do grupo, estimula seus subordinados com fatos, elogios e críticas. Liderança Liberal: Mínima participação do líder e ele não avalia o curso das decisões, total liberdade para a tomada de decisões grupais ou individuais. A participação do líder em debates é limitada apresentando apenas alternativas ao grupo, esclarecendo que poderia fornecer informações desde que solicitada. Tanto a divisão das tarefas quanto a escolha dos colegas ficam por conta do grupo. Na pesquisa, os autores identificaram que a maioria dos entrevistados optaram pelo estilo de liderança democrático e no contexto da cultura organizacional a maior parte dos sujeitos da pesquisa enxergam a empresa como uma extensão de si mesmos, sentem-se satisfeitos com o que conseguem realizar na organização e colaboram ativamente uns com os outros, os profissionais buscam aproveitar o máximo possível do trabalho em equipe. Os objetivos individuais e da empresa estão e os líderes criam líderes novos.

Os estudos de Barreto et al. (2013) e Gonçalves et al. (2015) evidenciaram a forma de liderança e cultura predominante em dois ambientes de trabalho distintos, mesmo em contextos diferentes as duas empresas têm predominância da liderança transformacional e da cultura clã, demonstrando que a relação destes dois fatores são tornam-se positivos na sobrevivência da empresa. Já nos estudos de Ramalheira (2013) e Reis et al. (2013) percebe-se a influência que o líder têm sobre o desempenho de sua equipe, ainda que cultura e liderança são fatores que trabalham juntos dentro deste contexto, evidencia-se também que não há cultura ou liderança que seja melhor ou pior, apenas que se adapte melhor ao ambiente, região e setor de uma organização. A seguir apresenta-se três estudos que trazem o impacto da liderança, cultura organizacional e outros fatores umas sobre as outras, demonstrando que esta é uma recíproca, ou seja, 
liderança influencia na cultura e cultura influencia na liderança, ao mesmo tempo que ambas influenciam na estrutura, no planejamento, na comunicação, na inovação e nos processos dentro da organização.

Kich e Pereira (2011) avaliaram como os fatores organizacionais, estrutura, liderança, cultura e comunicação influenciam no processo de implantação do Planejamento Estratégico. Foi um estudo de caso único, com enfoque qualitativo, por análise documental, entrevistas semiestruturadas em profundidade, questionário e observação sistemática. A empresa analisada foi a Santa Luzia Laboratório Médico. A organização tem uma estrutura hierárquica bem definida, observando-se que o fundador é a maior liderança dentro da organização e trabalha delegando funções e confiando em seus subordinados. Nos níveis hierárquicos subsequentes ao diretor-presidente (fundador) cada líder tem um estilo de liderança, enquadrando-se cada um no setor que atua e contribuindo para o crescimento da empresa.

No estudo percebeu-se que o fundador exerceu grande impacto no desenvolvimento da cultura da empresa, considerada uma cultura forte e enraizada e há poucas subculturas, o que contribui para que os resultados e objetivos organizacionais sejam atingidos; e influenciou no desenvolvimento da estrutura da organização. Outro ponto fundamental no contexto deste estudo envolve o processo de comunicação, visto a necessidade de transformação e envolvimento exigido pela implantação de um Planejamento Estratégico, e na Santa Luzia Laboratório Médico a comunicação entre o topo e a base acontece sem dificuldades e nos dois sentidos. Os autores observaram que para uma empresa implantar seu Planejamento Estratégico de forma eficaz precisa que o planejamento esteja alinhado com sua cultura organizacional e integrado a sua estrutura. A empresa deve ter uma comunicação eficaz e ter a presença de uma liderança envolvida no processo. Os autores resumem as influências de cada fator dentro da organização da seguinte forma: a maior liderança da organização influenciou no desenvolvimento da estrutura e da cultura da empresa; subsequentemente a estrutura influencia nas outras lideranças e nos processos de comunicação; e a comunicação é espelho da cultura organizacional. Os fatores organizacionais estrutura, liderança, cultura e comunicação se interrelacionam e um influencia na formação do outro.

O estudo de Teza et al. (2013) apresentou um estudo de caso sobre a influência da estratégia, da liderança e da cultura sobre o processo de inovação em uma empresa desenvolvedora de produtos para o lar. No estudo foi entrevistado um grupo focal de funcionários em uma organização, oriundos de diversos setores, e analisados documentos e feitas observações não participante. Os autores evidenciam que o processo de inovação proposto como estratégia pela empresa é possível devido a liderança e cultura que favorecem e contribuem para a criação e novas ideias de seus colaboradores.

A empresa tem como estratégia selecionar oportunidades e gerar novas ideias que estão alinhadas com os objetivos da mesma; o líder principal da 
organização delega autonomia para experienciar novos processos e métodos e contribui com uma cultura inovadora que visa implantar estratégias que busquem inovação; e no âmbito da cultura, os funcionários buscam algo novo ou melhor continuamente, há um trabalho colaborativo entre as pessoas e os setores que é incentivado pelos líderes. $\mathrm{O}$ alinhamento dos três fatores estratégia, cultura e liderança - contribuem para o processo de inovação desejado pela organização e pela sobrevivência da mesma no setor que atua.

Outro estudo relevante foi o de Dorow et al. (2013), que objetivou apresentar os fatores que impedem que o processo de geração de ideias aconteça na organização, visto que elas são insumos para a inovação. A abordagem metodológica caracterizou-se como um estudo exploratório, descritivo e qualitativo, realizado por entrevista aplicada a dois gerentes de uma empresa de pequeno porte que trabalha com inovação. No estudo os autores identificaram que a empresa fornece ferramentas e tempo para a geração de ideias, porém algumas pessoas têm dificuldades de expor suas ideias, consideraram este um fator da cultura pessoal, já que a cultura da empresa favorece e valoriza novas ideias. Os líderes possuem perfil inovador que contribui para os objetivos da organização. Concluíram que a autonomia, os treinamentos e a promoção de técnicas para a geração de ideias são capazes de estimular a gestão da inovação, porém as pessoas precisam ser preparadas para a mudança.

O estudo de Silva Júnior, Vasconcelos e Silva (2010), que segue, traz a comparação entre a visão dos líderes e liderados sobre os estilos de liderança encontrados em uma mesma empresa, demonstrando que é preciso haver um processo de comunicação entre equipe e chefia para que não haja divergência entre ambos, ao mesmo tempo identificaram a necessidade de diferentes formas de lideranças para que a organização se desenvolva.

Silva Júnior, Vasconcelos e Silva (2010) descreveram e analisaram a operacionalização do processo de desenvolvimento organizacional (DO), verificando os impactos na formação de lideranças em uma empresa brasileira do setor de papel e celulose. A metodologia foi uma pesquisa-ação do tipo colaborativa, com observação participante envolvendo 277 líderes da organização. Os autores identificaram os diferentes estilos de liderança na empresa:

Coercitivo: Este estilo se baseia em "ordens" ao invés de "orientação" e utiliza pouco diálogo. Um monitoramento próximo é apoiado por um feedback negativo, coercitivo, com uma ameaça implícita, se não explícita.

Democrático:Seuprincipalobjetivoéconstruirumcomprometimento através do consenso. Baseia-se na habilidade dos empregados em estabelecer suas próprias direções e em resolver seus conflitos de maneira construtiva. 
Afetivo: O principal objetivo do líder afetivo é criar harmonia e evitar o conflito. Um gestor que utiliza o estilo afetivo dispensa muito tempo cultivando relacionamento com os liderados.

Dirigente: Este estilo se baseia no diálogo com os outros, assim como na perspectiva singular do gestor sobre o negócio para que seja estabelecida uma visão. O gestor mantém os outros engajados, assegurando a eles que a direção é de interesse de longo prazo.

Treinador: $\mathrm{O}$ principal objetivo do estilo treinador é o desenvolvimento, dos outros, de longo prazo. Um gestor que utiliza este estilo ajuda os indivíduos a identificar seus pontos fortes e suas fraquezas, ajudando o empregado a estabelecer um plano de desenvolvimento e promovendo apoio e feedback constantes (SILVA JR.; VASCONSELOS; SILVA, 2010, p. 27, grifo dos autores).

Os autores constataram que na visão dos líderes o estilo que predomina na empresa os estilos democrático e afetivo, porém os liderados enxergam a predominância dos estilos coercitivo, democrático e afetivo. O estilo que menos foi percebido dentro da organização foi o modelador. Silva Júnior, Vasconselos e Silva (2010) destacam que a presença de mais um estilo de liderança é fundamental para a melhoria do processo gerencial, mas evidenciam que o desenvolvimento de outros estilos pouco presentes na empresa pode impactar na cultura organizacional ameaçando a estabilidade do sistema social, portanto qualquer estratégia de renovação de lideranças precisa considerar os aspectos culturais para que o processo de desenvolvimento organizacional tenha êxito.

Não há como falar em liderança sem contextualizar o processo sucessório, sobre este aspecto evidencia-se o estudo de Estol e Ferreira (2006) que demonstra dois formatos de sucessão em três unidades de uma mesma organização, demonstrando que a liderança também influencia neste processo, porém enfatiza-se que mesmo havendo dois processos evidentemente distintos entre si não impedem o sucesso da sucessão.

Estol e Ferreira (2006) investigaram a relação entre o processo sucessório e a cultura organizacional em uma empresa familiar brasileira. $\mathrm{O}$ método foi a aplicação de um questionário a 197 trabalhadores de uma empresa ramo de distribuição de alimentos, bebidas e produtos de limpeza, a qual foi dividida em três unidades para atender aos propósitos da pesquisa. Sendo que a unidade 1, a administração dos negócios era compartilhada pelo filho do dono e fundador e por um diretor regional com larga experiência na organização. Na unidade 2, a administração era compartilhada pelo filho do fundador e por um diretor regional recrutado no mercado para o cargo. A unidade 3 estava sendo gerenciada pelo filho do fundador com a presença direta dele, que ainda participava dos processos decisórios. Os autores trouxeram como resultados que a percepção dos respondentes gerenciados pelo sucessor do fundador e pelo profissional recrutado no mercado (Unidade 2) apresentou diferenças significativas comparando com os membros das outras unidades, a Unidade 2 entendeu que a empresa expressa maior profissionalismo competitivo, processo 
de humanização do local de trabalho, voltada a práticas organizacionais de recompensa e treinamento, melhor relacionamento com o cliente. Como as três unidades estavam em processo sucessório e este era diferenciado a percepção dos liderados sobre a cultura organizacional também era percebida de forma diferente, já que o sucessor da Unidade 2 não vivenciou os conhecimentos do fundador como os sucessores das outras duas unidades, criando crenças e valores diferentes das mantidas pelo fundador/dono. Por fim, concluíram que a origem (fundador), o treinamento e a experiência profissional do sucessor podem afetar a cultura organizacional de uma organização.

Por fim, há de se concluir que liderança influencia na cultura, e cultura influencia na liderança, não há uma liderança ou uma cultura certa ou errada, apenas culturas e lideranças que melhor se adequam a uma determinada situação.

\section{CONSIDERAÇÕES FINAIS}

Este estudo objetivou analisar na literatura a influência que a cultura organizacional tem sobre a atuação dos líderes empresariais. No contexto do objetivo proposto percebeu-se que cultura e liderança se confundem no contexto da literatura, visto que o impacto ocorre da cultura sobre a liderança e da liderança sobre a cultura. Uma vez que o fundador da empresa ainda é líder da mesma, este influenciará na criação da cultura organizacional e, por consequência, a cultura influenciará nos gestores dos setores, também considerados líderes.

A liderança sofre influência da cultura e das subculturas, que podem haver dentro da organização, e a escolha da liderança em uma determinada empresa é influenciada por diversos fatores: região onde a organização localizase, setor que o líder irá atuar, setor que a empresa atua, cultura da empresa, necessidade de mudanças, entre outros. Porém não há uma liderança ou uma cultura que seja melhor ou pior de modo geral, apenas lideranças e culturas que melhor se adaptem ao contexto atual da organização e a necessidade tanto do setor como da empresa.

\section{REFERÊNCIAS}

AAKER, David A.; KUMAR, V.; DAY, George S. Pesquisa de marketing. São Paulo: Atlas, 2004.

BARRETO, Leilianne M.T.S. et al. Cultura organizacional e liderança: uma relação possível? R. Adm., São Paulo, v. 48, n. 1, p. 34-52, 2013.

BONEL, Claudio. Os três tipos mais comuns de liderança. Administradores, 2013. Disponível em: <http:/ /www.administradores.com.br/artigos/negocios/os-3-tiposmais-comuns-de-lideranca/72986/ >. Acesso em: 28 out. 2016. 
CHIAVENATO, Idalberto. Gestão de pessoas. Rio de Janeiro: Elsevier, 2004.

CHIAVENATO, Idalberto. Gestão de pessoas: o novo papal dos recursos humanos nas organizações. 3. ed. Rio de Janeiro: Campus, 2010.

CHIAVENATO, Idalberto. Introdução à teoria geral da administração: uma visão abrangente da moderna administração das organizações. 7. ed. rev. e atual. Rio de Janeiro: Elsevier, 2003.

DOROW, Patricia F. et al. Barreiras e facilitadores para a geração de ideias. Revista Eletrônica de Estratégia \& Negócios, Florianópolis, v.6, n.3, set./dez.2013.

ESTOL, Kátia M.F.; FERREIRA, Maria C. O Processo Sucessório e a Cultura Organizacional em uma Empresa Familiar Brasileira. RAC, v. 10, n. 4, p. 93-110 out./ dez. 2006.

GIL, Antonio Carlos. Métodos e técnicas de pesquisa social. 6. ed. São Paulo: Atlas, 2008.

GIMENES, A.M. et al. A importância da liderança nas organizações. Unesul, v. 33, n. 14, p. 1.14, 2015. Disponível em: <https: / / www.inesul.edu.br/revista/arquivos/arqidvol_33_1426538800.pdf >. Acesso em: 20 out. 2016.

GONÇALVES, Andressa et al. A relação entre liderança e cultura organizacional: um estudo realizado em uma IES. GEPROS. Gestão da Produção, Operações e Sistemas, Bauru, Ano 10, n. 2, p. 85-100, abr./jun. 2015.

GUEDES, Vânia L. S.; BORSCHIVER, Suzana. Bibliometria: uma ferramenta estatística para a gestão da informação e do conhecimento, em sistemas de informação, de comunicação e de avaliação científica e tecnológica. In: PROCEEDINGS CINFORM ;ENCONTRO NACIONAL DE CIÊNCIA DA INFORMAÇÃO, IV. Salvador, Bahia, 2005.

KICH, Juliane I.D.F.; PEREIRA, Mauricio F. A influência da liderança, cultura, estrutura e comunicação organizacional no processo de implantação do planejamento estratégico. Cad. EBAPE.BR, v. 9, nº 4, artigo 6, Rio de Janeiro, Dez. 2011.

MALHOTRA, Naresh. Pesquisa de marketing: foco na decisão. 3. ed. São Paulo: Pearson Prentice Hall, 2011.

RAMALHEIRA, Pedro R.S. O impacto da cultura portuguesa e da pro atividade na liderança: um estudo exploratório. 2013. 154f. Dissertação (Mestrado em Planejamento e Gestão Estratégica) - Universidade Autônoma de Lisboa, Portugal, 2013.

REIS, Patricia N.C. et al. O impacto da liderança na construção da cultura organizacional: um estudo de caso entre alunos de uma IES privada. In: SIMPÓSIO DE EXCELÊNCIA EM GESTÃO E TECNOLOGIA, IX. Rio de Janeiro: Associação Educacional Dom Bosco, 2012. 
SILVA JUNIOR, Annor; VASCONCELOS, Kátia C.A.; SILVA, Priscilla O.M.

Desenvolvimento organizacional e a formação de lideranças: um estudo no setor de papel e celulose. R. Adm. FACES Journal, Belo Horizonte, v. 9, n. 2, p. 15-31, abr./jun. 2010.

TEZZA, Piery et al. Direcionadores do processo de inovação: o papel da estratégia, liderança e cultura. Navus - Revista de Gestão e Tecnologia. Florianópolis, SC, v. 3, n. 2, p. 77 - 88, jul./dez. 2013.

VERGARA, Sylvia Constant. Projetos e relatórios de pesquisa em administração. 7 . ed. São Paulo: Atlas, 2006. 